\title{
A Study on the Application of Pro Grip Self- Fixating Mesh in Patients with Inguinal Hernia Operated by the Lichtenstein Method
}

\author{
Dr Gordana Bozinovska Beaka
}

General Surgery Specialist

\begin{abstract}
Introduction: Inguinal hernia o rhernia inguinalis is a protrusion of contents in the abdominal cavityorpreperitoneal fat tissue through a defect of the transverse fascia in the groin above the inguinal ligament. There are two ways to resolve inguinal hernia: the first is by direct suture of the defect which increases tissue tension, the second is by placement of self-fixating mesh at the place of the defect. As defined, a surgical mesh is a synthetic alloplastic material used for strengthening of the abdominal cavity. Aim of the study: This study reviews patients withapplied ProGripself-fixating mesh, operated by the Lichtenstein method. Material and methods: It is a randomized clinical study, in which a total of40patients with inguinal herniaare analyzed, operated by the Lichtenstein method with the application of ProGripself-fixating mesh. The parameters observed in patients were: sex and age of the patient, perioperative period, intensity of postoperative pain, postoperative mobilization and days of postoperative hospitalization.The pain intensity will be measured using a visual analog scale (VAS), by patient's self-evaluation in range from 1 to 10.
\end{abstract}

Keywords: Pro Grip, self-fixating mesh, inguinal hernia, Lichtenstein method

\section{Introduction}

More than twenty million patients worldwide undergo inguinal hernia surgery annualy, applying different surgical techniques.(1).Diagnosisfor inguinal hernia is usually establishedby physical examinationof the patientin a standing position, and in unclear circumstances it is necessary to makeadditional examinations such as: ultrasonography, computed tomography (CT), magnetic resonance imaging(MRI) or herniogrhaphy(7).The only possible treatment for inguinal hernia is surgical.There are two ways to surgically resolve inguinal hernia $(2,3,4)$ :with adirect suture of the defect on the abdominal wall, which increases the tension of the tissue where the suture is done(which may lead to ischemia of the sewing edgeswith sequential occurrence of intensive pain); the other way is by placing a surgical mesh where the defect of the abdominal cavity is. This method is used for over 50 years and it is called tension free technique $(9,10,12)$. The modern era of hernioplasty began about 50 yearsago, with the use of monofilament woven mesh - which isa synthetic alloplastic materialused for strengthening the abdominal cavity and it can be made of biologic or synthetic material or it could be a combination of both $(5,6)$. The mesh needs to meet certain standards in order for it to be placed, such as: tobe permanent, to be able to restore integrity of the abdominal cavity, to be easy to handle, to have a solid integration in the native tissues, to have a low degree of foreign body reaction, to be resistantto infection and to be able toadjust and adapt to the natural structures that they cover(11).

\section{Aims of the Study}

The aim of this study is to get results from patients with inguinal hernia; operated by the Lichtenstein method, where a ProGrip mesh is set, in order to see to which extent does this self-fixating mesh meet the criteria from a practical aspect.

\section{Material and Methods}

The Pro Gripmesh is a semi-absorbable self-fixating (selfadhesive) polypropylene monofilament mesh made of polypropylene monofilament and absorbable component PLA (polylactic acid) in the form of micro hooks, which are hooked onto the tissuethusfixating the mesh.The technique of using this mesh is called tension freetechnique. In the moment of application, the micro hooks anchor themselves in the tissue and that is how they fixate the mesh(8). The mesh is previously formed in an oval shape with overlap and funiculus opening, so it is suitable for direct application through front Lichtenstein technique(8). Because of the psychological security of the surgeon you may or may not have to put a seam on pubis.At the moment of application the pore size is $1,6 \times 1,0 \mathrm{~mm}$ and the weight is $70 \mathrm{gr} / \mathrm{m} 2$ which makes the mesh one with optimal porosity and moderately heavy. The PLA component takes up to $50 \%$ of the mesh and it begins to resorb immediately after application.At the beginning, the resorption is minimal, and as time passes the resorption intensifies and the mesh will be completely absorbed in a period of 15 months, during which cellular incorporation of the mesh occurs in the tissue.After the resorption, the polypropylene component remains and the size of its pores is1, $6 \times 1,1 \mathrm{mmand}$ their weight is $40 \mathrm{gr} / \mathrm{m} 2$, categorizing it as a lightweight mesh with optimal porosity. The thickness of the mesh before resorption is $1.4 \mathrm{~mm}$ and after resorption is $0,6 \mathrm{~mm}$ which is suitable for Tacker fixation, but this is irrelevant since there is no need of additional fixation.The absence of fixation with suturesor Tackerseliminates the possibility of damage to the sensitive nerve and reduces the intensity of the post-operative pain for the patient.

The patients in this study were operated under general anesthesia, and the study was made in the General City Hospital of Skopje- 8th September, at the department of digestive surgery.40 patients, who were randomly chosen, were operated and they all had to meet certain criteria. 


\section{International Journal of Science and Research (IJSR) ISSN (Online): 2319-7064 \\ Index Copernicus Value (2013): 6.14 | Impact Factor (2015): 6.391}

Inclusion criteria were patients with responsible in guinal hernia at the age of 18 to 80 years, all of which had to agree to participate in the study. Exclusion criteria were:patients with clenched inguinal hernia, patients on chemotherapy, patients on immunosuppressive therapy, patients with comorbid conditions that lead to increased intra-abdominal pressure (as cites in the abdominal cavity, COPD), patients with comorbid conditions followed by pain, pregnant women, patients who did not sign the agreement to participate in the study. The parameters observed in patients were sex and age of the patient, peri operative period, intensity of postoperative pain, postoperative mobilization and days of postoperative hospitalization. The pain intensity was measured using a visual analog scale (VAS), by patient's self-evaluation in range from 1 to 10 , where $0=$ without pain, 2 = presence of mild pain, $4=$ presence of moderate pain, $6=$ presence of unpleasant pain, $8=$ presence of strong pain, $10=$ the presence of very strong pain. If a patient ranked their pain above 4, they were given analgesic therapy. Postoperative pain intensity was measured on the first and second postoperative day.

\section{Results}

40 patients were participants in the study, 38(95\%) of which are male and 2(5\%) are female. The average age of the patients is $45.67 \pm 15.6$ years (the minimum age is 18 , the maximum age is 70 years). The age of the patients was also analyzed in three groups, patientsyounger than 34 with a total of $11(27.5 \%)$, patients at the age of 35 to 54 with a total of 13 (32.5\%), and patientsolder than 55 with a total of $16(40 \%)$.

Table

\begin{tabular}{|c|c|c|c|}
\hline \multirow{2}{*}{ Variable } & \multicolumn{3}{|c|}{ Descriptive statistics } \\
\cline { 2 - 4 } & mean \pm SD & min - max & median (IQR) \\
\hline preoperative period (min) & $32.5 \pm 4.7$ & $25-40$ & $32.5(30-35)$ \\
\hline $\begin{array}{c}\text { postoperative mobilization } \\
\text { (hours) }\end{array}$ & $7.3 \pm 3.1$ & $24-\mathrm{Apr}$ & $7(6-8)$ \\
\hline $\begin{array}{c}\text { postoperative days of } \\
\text { hospitalization }\end{array}$ & $2.4 \pm 0.7$ & 4-Jan & $2(2-3)$ \\
\hline
\end{tabular}

The average VAS score for pain intensity immediately after the intervention is $3.8 \pm 1.5$, whereas 2 days after the intervention a lower average score of $3.1 \pm 1.1$ was registered.

Table

\begin{tabular}{|c|c|c|}
\hline \multirow{2}{*}{ Period of measurement } & \multicolumn{2}{|c|}{ Descriptive statistics - VAS } \\
\cline { 2 - 3 } & mean \pm SD & min - max \\
\hline Postoperatively & $3.8 \pm 1.5$ & 8-Feb \\
\hline 2 days postoperatively & $3.1 \pm 1.1$ & 6-Feb \\
\hline
\end{tabular}

${ }^{\mathrm{a}} \mathrm{p}$ (Wilcoxon Matched Pairs Test) ${ }^{* *} \mathrm{p}=0.007$

The VAS scale was analyzed immediately after surgery, 2 days afterwards and then compared to the percentage of scores. $30 \%$ of the patientshada pain score of 2 immediately after the intervention and $47.5 \% \quad 2$ days after the intervention; a score of 4 had $52.5 \%$ of patients immediately after the intervention and 50\% 2 days after the intervention.Apain score of 6was registered in $15 \%$ of the patientsimmediately after the intervention and only 1 patient
2 days after the intervention.Only 1 patient had a score with the value 8 on the VAS scale immediately after the intervention.

The statistical analysis was confirmed to be significant due to the difference on the VAS scale between the immediate postoperative period and 2 days after the surgery $(p=0.007)$.

Table

\begin{tabular}{|c|c|c|}
\hline $\begin{array}{c}|c| \\
\text { VAS } \\
\text { (score) }\end{array}$ & $\begin{array}{c}\text { VAS } \\
\text { postoperatively } \\
\text { N (\%) }\end{array}$ & $\begin{array}{c}\text { VAS - 2 days } \\
\text { postoperatively } \\
\text { N (\%) }\end{array}$ \\
\hline 2 & $12(30)$ & $19(47.5)$ \\
\hline 4 & $21(52.5)$ & $20(50)$ \\
\hline 6 & $6(15)$ & $1(2.5)$ \\
\hline 8 & $1(2.5)$ & \\
\hline
\end{tabular}

${ }^{\mathrm{a}} \mathrm{p}$ (Wilcoxon Matched Pairs Test)**p $=0.007$

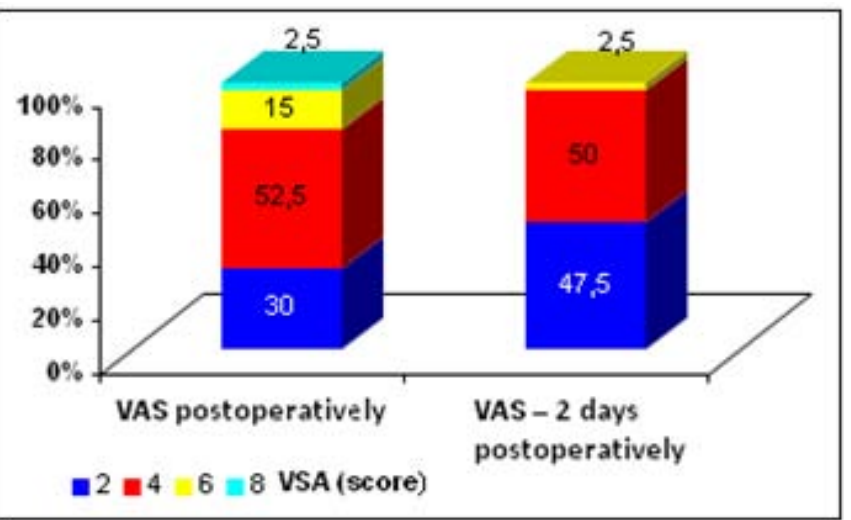

The age of the patients had an insignificant impact on the average perioperative period( $\mathrm{p}>0.05)$. In the group of patients at the age of 35-54 we registered an insignificantly longer average perioperative period in relation to the remaining two other age groups (31.8 \pm 4.6 , $34.2 \pm 4.9$, 31.6 \pm 4.3 consequently).

Table

\begin{tabular}{|c|c|c|}
\hline \multirow{2}{*}{$\begin{array}{c}\text { age groups } \\
\text { (years) }\end{array}$} & Descriptive statistics- preoperative period(min) \\
\cline { 2 - 3 } & mean \pm SD & $\min -\max$ \\
\hline$\leq 34$ & $31.8 \pm 4.6$ & $25-40$ \\
\hline $35-54$ & $34.2 \pm 4.9$ & $25-40$ \\
\hline $55>$ & $31.6 \pm 4.3$ & $25-40$ \\
\hline \multicolumn{3}{|c|}{${ }^{\mathrm{b}} \mathrm{p}=0.27$} \\
\hline
\end{tabular}

Postoperative mobilization significantly depended on the age of the patients ( $p<0.001)$. Postoperative mobilization was shortest in the youngest age group, patients younger than 34 years $($ mean $=5.7 \pm 0.7$; median $=6$, rang 5-6), and longest in the oldest group of patients, thoseover55 years ( mean $=9.3 \pm 4.2$; median $=8$, rang 7.5-10).

Table

\begin{tabular}{|c|c|c|c|}
\hline \multirow{2}{*}{$\begin{array}{c}\text { Age } \\
\text { groups } \\
\text { (years) }\end{array}$} & \multicolumn{3}{|c|}{ Descriptive statistics - postoperative mobilization } \\
\cline { 2 - 4 } (hours) & mean \pm SD & min - max & median (IQR) \\
\hline$\leq 34$ & $5.7 \pm 0.7$ & 7-May & $6(5-6)$ \\
\hline $35-54$ & $6.3 \pm 1.1$ & 8-Apr & $6(6-7)$ \\
\hline $55>$ & $9.3 \pm 4.2$ & 24-Jun & $8(7.5-10)$ \\
\hline \multicolumn{4}{|c}{$c \mathrm{p}<0.001$} \\
\hline
\end{tabular}




\section{International Journal of Science and Research (IJSR) \\ ISSN (Online): 2319-7064 \\ Index Copernicus Value (2013): 6.14 | Impact Factor (2015): 6.391}

'p (Kruskal-Wallis test)

A positive, significant correlation was found between the patients' age and the time of postoperative mobilization expressed in hours (Pearsonr $=57 \mathrm{p}<0.001$ ).

Image. Correlation between the age of patients and the time during the postoperative mobilization

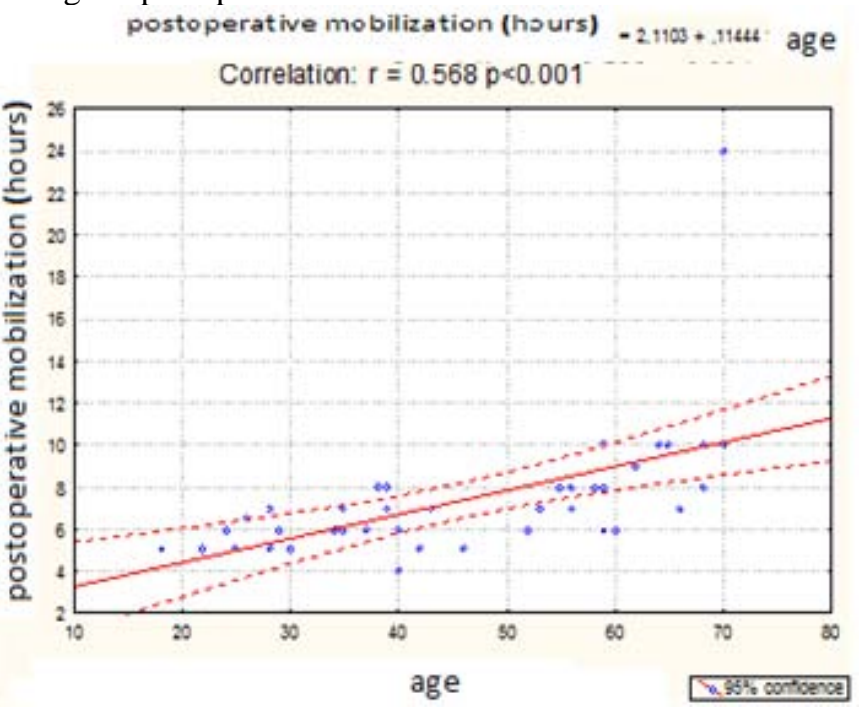

The length of hospital stay postoperatively insignificantly depended on the patients' age $(\mathrm{p}>0.05)$.

Table

\begin{tabular}{|c|c|c|c|}
\hline \multirow{2}{*}{$\begin{array}{c}\text { Age } \\
\text { groups } \\
\text { (years) }\end{array}$} & \multicolumn{3}{|c|}{$\begin{array}{c}\text { Descriptive statistics - postoperative days of } \\
\text { hospitalization }\end{array}$} \\
\cline { 2 - 4 } & mean \pm SD & min - max & median (IQR) \\
\hline$\leq 34$ & $2.5 \pm 0.7$ & 4-Feb & $2(2-3)$ \\
\hline $35-54$ & $2.1 \pm 0.7$ & 4-Jan & $2(2-2)$ \\
\hline $55>$ & $2.4 \pm 0.7$ & 4-Feb & $2(2-3)$ \\
\hline \multicolumn{4}{|c|}{$c \mathrm{p}=0.2$} \\
\hline
\end{tabular}

cp (Kruskal-Wallis test)

The intensity of pain quantified by the VAS scale, measured immediately after the intervention and 2 days postoperatively, insignificantly depended on the age of the patients ( $>0.05$ ). In the oldest age group, an insignificantly stronger painwas registeredin both analyzed time points, compared to theother age groups.

p (Kruskal-Wallis test)

Table

\begin{tabular}{|c|c|c|c|c|c|c|}
\hline \multirow{2}{*}{ age } & \multicolumn{3}{|c|}{ VAS postoperatively } & \multicolumn{3}{c|}{ VAS 2 days postoperatively } \\
\cline { 2 - 7 } & mean \pm SD & min - max & median (IQR) & mean \pm SD & min - max & median (IQR) \\
\hline$\leq 34$ & $3.3 \pm 1$ & 4-Feb & $4(2-4)$ & $2.9 \pm 1$ & 4-Feb & $2(2-4)$ \\
\hline $35-54$ & $3.8 \pm 1.5$ & 6 -Feb & $4(2-4)$ & $2.9 \pm 1.5$ & $4-F e b$ & $2(2-4)$ \\
\hline $55>$ & $4.1 \pm 1.7$ & $8-F e b$ & $4(3-5)$ & $3.75 \pm 1.2$ & $6-F e b$ & $4(2-45)$ \\
\hline & \multicolumn{3}{|c}{ c $\mathrm{p}=0.4$} & \multicolumn{3}{c}{${ }^{\mathrm{c}} \mathrm{p}=0.5$} \\
\hline
\end{tabular}

Table

\begin{tabular}{|c|c|c|c|}
\hline \multirow{2}{*}{$\begin{array}{c}\text { VAS 2 days } \\
\text { postoperatively }\end{array}$} & \multicolumn{3}{|c|}{ Age groups (years) } \\
\cline { 2 - 4 } & $\leq 34$ & $35-54$ & $55>$ \\
\cline { 2 - 4 } & $\mathrm{n}(\%)$ & $\mathrm{n}(\%)$ & $\mathrm{n}(\%)$ \\
\hline $2 \mathrm{n}=19$ & $6(54.55)$ & $7(53.85)$ & $6(37.5)$ \\
\hline $4 \mathrm{n}=20$ & $5(45.45)$ & $6(46.15)$ & $9(56.25)$ \\
\hline $6 \mathrm{n}=1$ & 0 & 0 & $1(6.25)$ \\
\hline \multicolumn{4}{|c|}{$\mathrm{c} \mathrm{p}=0.5$} \\
\hline
\end{tabular}

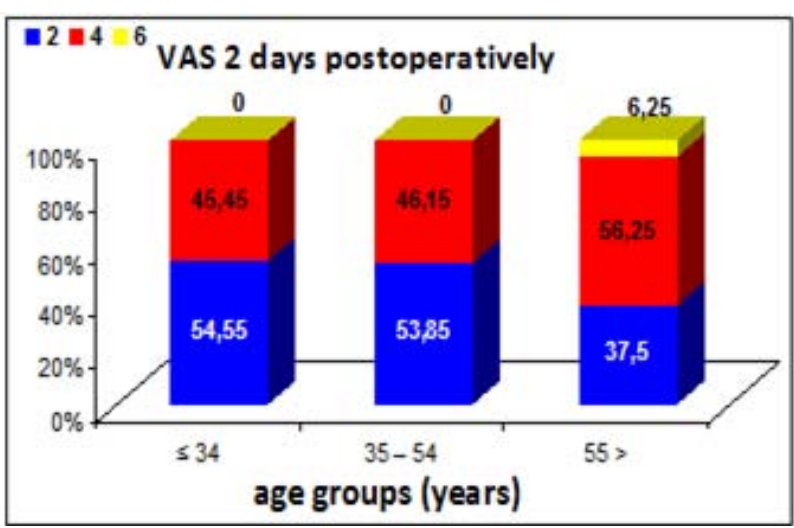

Statistical Analysis

For statistical analysis of data obtained during the study, a database was created in the SPSS17, 0program forWindows. Testing of the distribution of data was done with Kolmogorov - Smirnov test. Categorical variables were displayed in absolute numbers and percentages, quantitative data were described with mean \pm SD, minu max, mediancoIQR.

To test the difference between the analyzed variables, parametric (Analysis of Variance) andnonparametric methods (Wilcoxon Matched pairs и Kruskal-Wallis ANOVA test) were used.

To determine the correlation, Pearson coefficient of $\mathrm{p}$ linear correlation was used. Forlevel of significance or importance, the value of $<0$, 05 was taken, and forhighly significant- the value of $\mathrm{p}<0,01$.

\section{Discussion}

The purpose of this randomized clinical study, was to estimate to which extent does the ProGrip mesh, as so-called self fixating mesh(which was applied in 40 patients operated by the Lichtenstein method), meets the criteria from a practical aspect. Multiple parameters were used, such asa visual analog scale (VAS)with self-evaluation to determine the intensity of pain.It was evident from the statistical analysis that there is a significant difference in VAS immediately after the intervention and2 days postoperatively $(p=0.007)$, i.e. there was a significant reduction in pain even on the second day after the surgery. The age of the patients had an insignificant impact on the perioperative period, but 
it played a major role in postoperative immobilization postoperative immobilization was the shortest in the youngest age group and longest in the oldest age group.Values obtained from this study suggest that the results of our department are very close to the results of world literature, which suggests that the ProGrip mesh meets the necessary requirements and is suitable for use in resolving inguinal hernia in daily surgical practice.

\section{References}

[1] Klinge U, Klosterhalfen B, Birkenhauer V, Junge K, Conze J, Schumpelick V. Impact ofpolymer pore size on the interface scar formation in a rat model. J SurgRes.2002;103:208-14.

[2] Collaboration EH. Mesh compared with non-mesh methods of open groin hernia repair: systematic review of randomized controlled trials. Br JSurg. 2000;87:8549.

[3] Grant AM; EU Hernia TrialistsCollaboration. Open mesh versus non-mesh repair of groin hernia: metaanalysis of randomised trials based on individual patient data [corrected]. Hernia. 2002; 6:130-6.

[4] vanVeen RN, WijsmullerAR, VrijlandWW, Hop WC, LangeJF, JeekelJ. Long- term follow-up of a randomized clinical trial of non-mesh versus mesh repair of primary inguinal hernia. Br JSurg. 2007; 94:506-10.

[5] Klinge U. Mesh for hernia repair. $\mathrm{Br} \mathrm{J}$ Surg. 2008;95:539-40. [PubMed]

[6] Burger JWA, Luijendijk RW, Hop WCJ, Halm JA, Verdaasdonk EGG, Jeekel J. Long-term follow-up of RCT of suture versus mesh repair of incisional hernia. Ann Surg. 2004;240:578-85. [PMC free article][PubMed]

[7] BradleyM, MorganD, PentlowB, Roe A. The groin Hernia-an ultrasound diagnosis? Ann R CollSurgEngl. 2003; 85:17-80.

[8] Covidien - Hernia Mesh Brochure

[9] LichtensteinIL, Shulman AG, Amid PK, Montllor MM. Thetension-free hernioplasty.AmJSurg. 1989; 157:18893

[10] SakorafasGH, HalikiasI, NissotakisC, Kotsifopoulos N, Stavrou A, Antonopoulos C, KassarasGA. Open tension freerepairof inguinal hernias; theLichtensteintechnique. BMC Surg. 2001; 1:3

[11] Goldstein HS: Selecting the right mesh. Hernia 1999, 3:23-26.

[12] Rutkow IM, Robbins AW. "Tension-free" inguinal herniorrhaphy: a preliminary report on the mesh plug technique. Surgery 1993;114:3 [PubMed: 8356522] 